\title{
Aplicação da ferramenta FMEA para a construção de uma asa de revestimento metálico
}

Luiz Felipe de Oliveira luizfelipeqds@gmail.com Universidade Federal do Pampa
(UNIPAMPA), Alegrete, Rio Grande do Sul, Brasil

\begin{abstract}
RESUMO
Failure Mode and Effect Analisys (FMEA) é considerado um dos métodos de análise de risco mais eficazes o qual tem sido amplamente adotado em diversos campos para as melhorias da segurança e a confiabilidade de sistemas. O presente estudo tem como objetivo montar uma matriz FMEA de uma asa de revestimento metálico. As metodologias empregadas no estudo consistem em análise bibliográfica e a realização de Focus Group para a determinação dos índices de severidade, de ocorrência e de detecção, podendo assim calcular o NPR e encontrar a relevância de cada modo de falha. Já para as ações de melhorias de cada modo de falha, também se utilizou a técnica de Focus Group com objetivo de encontrar essas ações. Como resultados deste estudo, têm-se como os modos de falha de maior relevância as longarinas, as nervuras e o acoplamento entre a asa e a fuselagem.
\end{abstract}

PALAVRAS-CHAVE: FMEA, Modos de falhas, Ações de melhorias, Análise de riscos. 


\section{INTRODUÇ̃̃O}

Anderson (2003), em seu trabalho, aborda que cada vez mais se busca uma vida com um ritmo acelerado, tanto que se ganha uma recompensa para quem se desloca o mais rápido possível de um lugar a outro. Viagens de longas distâncias hoje em dia não consomem tanto tempo quanto antigamente e esse feito se deve a um grande avanço tecnológico na "arte" a qual se chama: voar. Segundo o mesmo autor, voar somente é possível devido à alta tecnologia utilizada na fabricação de aeronaves durante essa última década vivida.

Sabe-se que as aeronaves são enormes facilitadoras de vidas, portanto o seu projeto deve ser muito bem feito e definido da melhor forma possível. Zorzo et al. (2015), descreve em seu trabalho que ao desenvolver uma aeronave, deve-se levar em conta partes imprescindíveis ao longo da execução do projeto como a: aerodinâmica, estabilidade e controle, cargas estruturais, desempenho e modelo tridimensional detalhado do projeto. Onde que para cada parte existe uma série de sistemas, subsistemas e componentes que são definidos durante o desenvolvimento das mesmas. Uns dos componentes mais importantes são as asas. São elas que vão garantir uma grande comodidade, conforto, economia, entre outros requisitos aos passageiros no decurso de um voo. Além disso, devese levar em conta a segurança a qual elas devem garantir durante o transporte.

Para a garantia de segurança utilizam-se recursos para que tenha o menor número possível de incoerências, ou seja, evitar erros. Como uma das principais ferramentas a fim de atingir esse objetivo tem-se o FMEA. Liu (2016) e Zhou et al. (2016) definem a Análise dos Modos de Falha e seus Efeitos (FMEA) como um tipo de análise de confiabilidade e técnica de gerenciamento de risco, o qual tem sido amplamente utilizado nos mais diversos campos, como aeroespacial, navegação, fabricação, química, etc.

A justificativa do presente trabalho se dá pela importância da utilização da matriz FMEA para o desenvolvimento de um projeto, ou produto, mostrando as falhas potenciais presentes nos componentes. Portanto, tem-se como problema de pesquisa: como montar uma matriz FMEA para uma asa de revestimento metálico?

O objetivo geral da pesquisa é montar uma matriz FMEA de uma asa de revestimento metálico. Onde se tem como objetivos específicos os seguintes itens: (I) Identificar os potenciais itens que podem ocorrer falha; (II) Determinar o ranking de severidade, ocorrência e defectibilidade; e (III) Definir as possíveis melhorias para cada modo de falha.

Tem-se como possíveis soluções para os problemas apresentados: $\mathrm{H} 1$ - O entendimento da montagem de uma matriz FMEA para uma asa de revestimento metálico. $\mathrm{H} 2$ - A realização de uma pesquisa bibliográfica para a obtenção dos possíveis componentes que podem ocorrer falhas. $\mathrm{H} 3-\mathrm{O}$ uso da técnica de Focus Group para a determinação dos rankings de Severidade, de Ocorrência e de Detecção com a finalidade de fazer o cálculo de cada ranking. H4 - A utilização da ferramenta Focus Group para a identificação das possíveis melhorias de cada modo de falha.

A motivação (o porquê da escolha do tema) do presente trabalho vem de poder entender como é feito uma asa de uma aeronave, quando a mesma está no decorrer de seu projeto, mais especificamente, no projeto detalhado e 
também contribuir em tornar público possíveis falhas que uma asa pode conter. O pensamento que inspira esse trabalho é frase dita por Samuel Johnson: "Há conhecimento de dois tipos: sabemos sobre um assunto, ou sabemos onde podemos buscar informação sobre ele".

\section{REVISÃO BIBLIOGRÁFICA}

Essa seção é desenvolvida partir de pesquisas em assuntos relacionados ao trabalho nas bibliografias disponíveis.

\section{CONCEITOS DE METODOLOGIA DE PROJETO E PRODUTO}

Segundo Rozenfeld et al. (2006), um produto é desenvolvido a partir de uma série de etapas, conforme mostradas na Figura 1, que são divididas em macro fases, sendo subdivididas em fases e atividades. As macro-fases são divididas em três fases e são denominadas de: Pré-Desenvolvimento, Desenvolvimento e Pós Desenvolvimento. Observa-se também que a macro fase de desenvolvimento é composta de 6 fases as quais são chamadas de: Planejamento de Projeto, Projeto Informacional, Projeto Conceitual, Projeto Detalhado, Preparação da Produção e Lançamento do Produto.

Figura 1 - Modelo de desenvolvimento de produto de Rozenfeld.

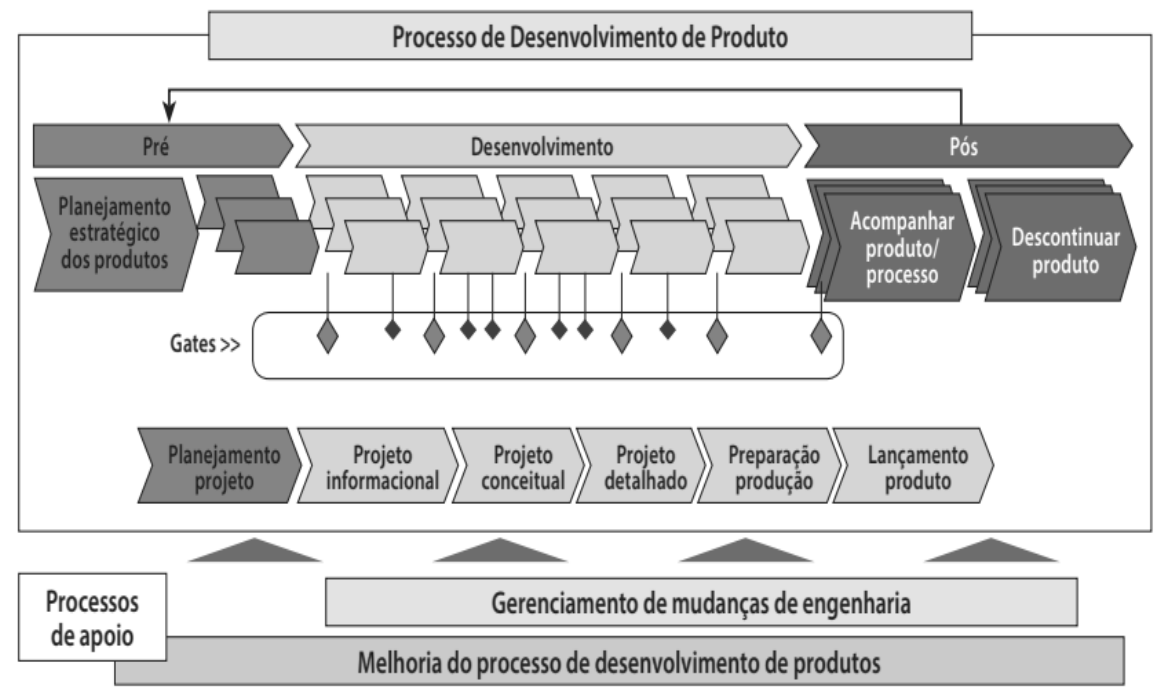

Fonte: Rozenfeld et al. (2006, p. 44)

Segundo Oliveira (2008), o desenvolvimento de um produto também se segue etapas bem definidas de projeto, onde cada etapa possui atividades de fase e, respectivamente, tarefas para cada atividade. A Figura 2 apresenta o modelo mencionado pelo autor. 
Figura 2 - Modelo de desenvolvimento de produto para Oliveira.

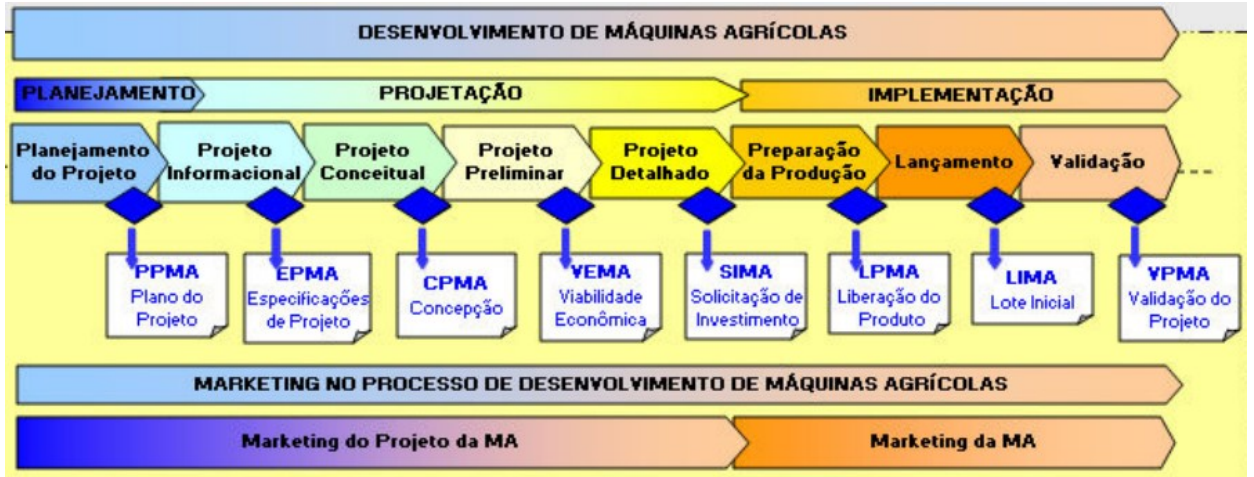

Fonte: Adaptado de Oliveira (2010, p. 4).

\section{FAILURE MODE AND EFFECTS ANALYSIS (FMEA)}

Segundo Bonamoni et al. (2012), a ferramenta FMEA surgiu no ano de 1949 para auxiliar na avaliação de equipamentos do exército americano. Já na década de 60, durante o projeto Apollo, a NASA aperfeiçoou a técnica inicial, juntamente com método para identificação e classificação, de forma sistemática, de falhas potenciais de produtos ou processos antes elas ocorressem. $O$ autor comenta em seu trabalho que mais tarde, no ano de 1972, a Ford Motor Company introduziu a ferramenta na indústria automobilística e difundiu seu uso para toda rede de fornecedores com a norma QS 101. Atualmente, a ferramenta é usada nas mais diversas áreas desde a indústria química até a ambiental.

Conforme Roos et al. (2007), atualmente, as organizações apresentam uma corrida em busca da qualidade, realidade esta justificada pela vantagem competitiva que ela proporciona frente as crescentes exigências dos clientes pelo reconhecimento da qualidade. Ou seja, cada vez mais se busca satisfazer os clientes nas fases de projeto fazendo com que as empresas não gastem dinheiro, e nem tempo, com alguns produtos defeituosos fabricados por elas mesmas.

Uma ferramenta que tem o objetivo de auxiliar essa busca por qualidade chama-se FMEA. É um método que ajuda a determinar um conjunto de ações corretivas ou ações que minimizem modos de falha em potencial. O FMEA pode identificar analisar e estimar possíveis falhas no sistema e os seus efeitos (AHIRE e RELKAR, 2012). De forma contundente, Bastos (2006) afirma que a sua utilização implica em minimização das chances do produto ou processo falhar, ou seja, a partir da aplicação da ferramenta, contribui-se diretamente, na dimensão confiabilidade.

Para Wang et al. (2018) existe uma abordagem FMEA convencional, bastante utilizada por ser de fácil compreensão, onde a avaliação de risco de cada modo de falha é implementada via RPN (número de prioridade de risco), obtida pela multiplicação do valor de cada fator de risco, ou seja, ocorrência (O), severidade (S) e detecção (D).

Carpinetti (2010) define que para a obtenção da matriz deve ser desenvolvida três etapas. A primeira etapa consiste em identificar falhas e definir as prioridades. Puente et al. (2002), desmembra esta etapa em dois grandes estágios, onde no primeiro estágio, são identificados possíveis modos de falhas de um produto, processo ou serviço e relacionados com suas respectivas causas e 
efeitos. Já no segundo estágio, é determinado o nível crítico, ou seja, a pontuação de risco destas falhas as quais posteriormente são colocadas em ordem. A ordem é estabelecida onde as falhas mais críticas permanecem em primeiro no ranking, sendo consideradas prioritárias devendo receber melhorias.

Já na segunda etapa, deve-se estabelecer um plano de ação com a finalidade de eliminar das falhas e, na terceira etapa deve-se analisar as falhas após a adesão de planos, conferindo se as ações propostas eliminaram ou diminuíram a ocorrência das causas das falhas.

Conforme já citado anteriormente, a determinação do nível crítico dos modos de falha realiza-se com base nos índices de severidade, ocorrência e detecção (PALADY, 2004). O procedimento FMEA atribui um valor numérico a cada risco associado a causar uma falha, usando severidade, ocorrência e detecção como métricas. Ao multiplicar a severidade pela ocorrência pela deteç̧ão do risco, obtém-se o RPN, que é valor o qual reflete a classificação de criticidade. (ARABIAN-HOSEYNABADI et al., 2010). Os quadros 1, 2 e 3 apresentam estes índices respectivamente.

Segundo Arabian-Hoseynabadi et al. (2010), a severidade refere-se à magnitude do efeito final de uma falha do sistema. Quanto mais grave for a consequência, maior será o valor da severidade atribuído ao efeito.

Quadro 1 - Escala de severidade.

\begin{tabular}{|c|c|}
\hline Escala de severidade dos efeitos dos modos de falha & Índice \\
\hline Efeito não percebido pelo cliente & 1 \\
\hline Efeito bastante insignificante, percebido por 25\% dos clientes & 2 \\
\hline Efeito insignificante, mas percebido por 50\% dos clientes & 3 \\
\hline Efeito moderado e percebido por 75\% dos clientes & 4 \\
\hline Efeito consideravelmente crítico, percebido pelo cliente & 5 \\
\hline Efeito consideravelmente crítico, que perturba o cliente & 6 \\
\hline Efeito crítico, que deixa o cliente um pouco insatisfeito & 7 \\
\hline Efeito crítico, que deixa o cliente consideravelmente insatisfeito & 8 \\
\hline Efeito crítico, que deixa o cliente totalmente insatisfeito & 9 \\
\hline Efeito perigoso, que coloca a vida do cliente em risco & 10 \\
\hline
\end{tabular}

Fonte: Adaptado de Palady.

Segundo o mesmo autor, a ocorrência refere-se à frequência que uma causa de falha é provável de ocorrer, descrita de forma qualitativa.

Quadro 2 - Escala de ocorrência.

\begin{tabular}{|c|c|}
\hline Escala de avaliação de ocorrência das causas e modos de falha & Índice \\
\hline Extremamente remoto, altamente improvável & 1 \\
\hline Remoto, improvável & 2 \\
\hline Pequena chance de ocorrência & 3 \\
\hline Pequeno número de ocorrências & 4 \\
\hline Espera-se um número ocasional de falhas & 5 \\
\hline Ocorrência moderada & 6 \\
\hline Ocorrência frequente & 7 \\
\hline Ocorrência elevada & 8 \\
\hline Ocorrência muito elevada & 9 \\
\hline Ocorrência certa & 10 \\
\hline
\end{tabular}

Fonte: Adaptado de Palady. 
A detecção refere-se à probabilidade de detectar a causa antes que ocorra uma falha.

Quadro 3 - Escala de detecção.

\begin{tabular}{|c|c|}
\hline Escala de detecção das causas e modos de falha & Índice \\
\hline Quase certo a detecção & 1 \\
\hline Probabilidade muito alta de deteç̧̃̃o & 2 \\
\hline Alta probabilidade de detecção & 3 \\
\hline Chance moderada de detecção & 4 \\
\hline Chance média de deteç̧ão & 5 \\
\hline Alguma probabilidade de deteç̧ão & 6 \\
\hline Baixa probabilidade de detecção & 7 \\
\hline Probabilidade muito baixa de detecção & 8 \\
\hline Probabilidade remota de deteção & 9 \\
\hline Detecção quase impossível & 10 \\
\hline
\end{tabular}

Fonte: Adaptado de Palady.

Conforme Kang et al. (2017), para analisar o modo de falha no procedimento de FMEA, essas três métricas de caracteres (severidade, detecção e ocorrência) devem ser empregadas. Essas métricas são dimensionadas para vários níveis e denotam valores específicos mostrados nos quadros acima. Multiplicando severidade, ocorrência e deteç̧ão, o número de prioridade de risco (RPN) é obtido para medir o risco do modo de falha e determinar os subconjuntos mais perigosos.

Yang et al. (2011), em seu trabalho, comenta que depois de analisar o impacto e as consequências de cada modo de falha, as vulnerabilidades do sistema podem ser confirmadas de acordo com a gravidade e probabilidade de ocorrência e detecção. Nesta base, recomendações para manutenção e melhoria de componentes relevantes são dadas e, portanto, a confiabilidade do sistema pode ser melhorada.

ASAS

Segundo Homa (2007), as asas de aeronaves têm a função de produzir a sustentação necessária durante o voo. São projetadas para serem muito fortes e muito leves, sendo um conjunto indispensável, que deve receber grande atenção durante a execução do projeto. A estrutura de uma asa é mostrada na Figura 3.

Figura 3 - Estruturas da asa.

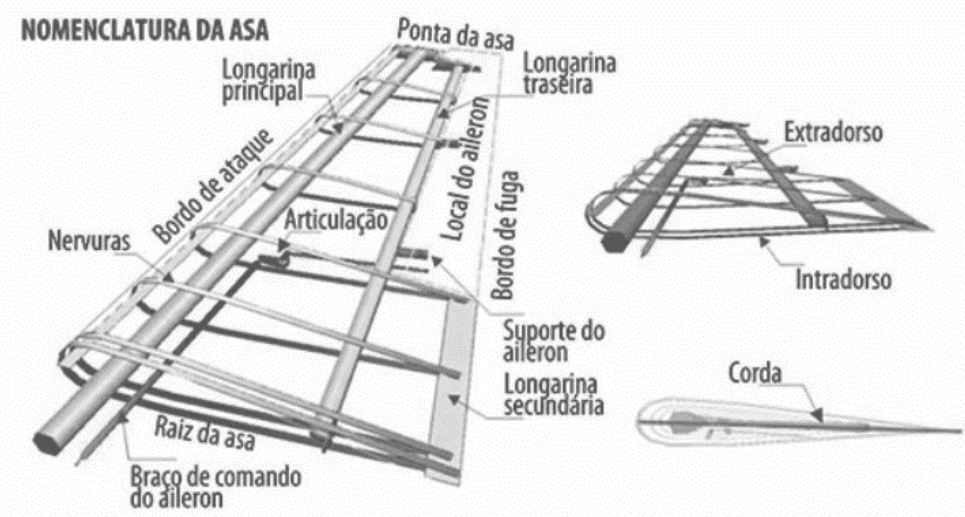

Fonte: Adaptado de Unisul (p. 49). 
Vale-se ressaltar que os principais componentes de uma asa estão em sua estrutura interna que são as longarinas e as nervuras.

As longarinas são os membros estruturais principais da asa, pois são elas que suportam toda a carga distribuída, além de pesos concentrados como exemplo o da fuselagem. Já as nervuras são componentes que dão o formato aerodinâmico á asa, além de transmitirem os esforços aerodinâmicos do revestimento para as longarinas.

Homa (2007) também comenta em seu trabalho que, além dos componentes mostrados na Figura 3, uma asa possui os demais itens citados a seguir:

- Flaps;

- Slats;

- Freios aerodinâmicos (spoilers);

- Revestimento.

Ressalta-se que o revestimento é de extrema importância na construção de uma asa, uma vez que se o revestimento não for estrutural, como telas, existem materiais que ajudam a suportar esforços de compressão e de tração como exemplo: montantes, reforços ou suportes estruturais aplicados às nervuras entre a longarina principal e a traseira.

No Quadro 3, apresenta-se o resumo da revisão bibliográfica, em ordem cronológica dos autores e suas contribuições.

Quadro 3 - Resumo da revisão bibliográfica, em ordem cronológica dos autores e suas contribuições.

\begin{tabular}{|c|c|c|c|c|}
\hline Ano & Autor(es) & Tema & Método & Resultados \\
\hline 2002 & Puente et al. & $\begin{array}{c}\text { Um sistema de } \\
\text { apoio à decisão } \\
\text { para aplicação do } \\
\text { FMEA }\end{array}$ & $\begin{array}{l}\text { Estudo de } \\
\text { caso }\end{array}$ & $\begin{array}{l}\text { Elabora um modelo de } \\
\text { decisão impreciso, } \\
\text { melhorando o sistema de } \\
\text { decisão inicial com a } \\
\text { introdução do elemento } \\
\text { de incerteza. }\end{array}$ \\
\hline 2004 & Palady & $\begin{array}{l}\text { Análise dos } \\
\text { Modos de Falha e } \\
\text { Efeitos: prevendo } \\
\text { e prevenindo } \\
\text { problemas antes } \\
\text { que ocorram } \\
\end{array}$ & $\begin{array}{l}\text { Documen-tal; } \\
\text { documen- } \\
\text { tação indireta. }\end{array}$ & $\begin{array}{c}\text { Apresentação e } \\
\text { desenvolvimento da } \\
\text { ferramenta FMEA }\end{array}$ \\
\hline 2006 & $\begin{array}{c}\text { Rozenfeld et } \\
\text { al. }\end{array}$ & $\begin{array}{l}\text { Gestão de } \\
\text { desenvolvimento } \\
\text { de produtos: uma } \\
\text { referência para a } \\
\text { melhoria do } \\
\text { processo }\end{array}$ & $\begin{array}{l}\text { Documen-tal; } \\
\text { documen- } \\
\text { tação indireta. }\end{array}$ & $\begin{array}{l}\text { Apresenta conceitos } \\
\text { sobre a gestão de } \\
\text { desenvolvimento de } \\
\text { projeto e produtos. }\end{array}$ \\
\hline 2006 & Bastos & $\begin{array}{l}\text { FMEA (Failure } \\
\text { Mode and Effect } \\
\text { Analysis) Como } \\
\text { Ferramenta de } \\
\text { Prevenção da } \\
\text { Qualidade em } \\
\text { Produtos e }\end{array}$ & $\begin{array}{l}\text { Estudo de } \\
\text { caso }\end{array}$ & $\begin{array}{l}\text { Identificação da operação } \\
\text { crítica, bem como a } \\
\text { identificação de ações } \\
\text { para atenuar, até mesmo } \\
\text { eliminar os potenciais } \\
\text { riscos. }\end{array}$ \\
\hline
\end{tabular}




\begin{tabular}{|c|c|c|c|c|}
\hline & & $\begin{array}{l}\text { Processos - Uma } \\
\text { Avaliação da } \\
\text { Aplicação em um } \\
\text { Processo } \\
\text { Produtivo de } \\
\text { Usinagem de } \\
\text { Engrenagem }\end{array}$ & & \\
\hline 2007 & Homa & $\begin{array}{c}\text { Aeronaves e } \\
\text { Motores } \\
\text { (Conhecimentos } \\
\text { Técnicos) } \\
\end{array}$ & $\begin{array}{l}\text { Documen-tal; } \\
\text { documen- } \\
\text { tação indireta. }\end{array}$ & $\begin{array}{l}\text { Apresenta conceitos } \\
\text { sobre os componentes de } \\
\text { aeronaves e motores. }\end{array}$ \\
\hline 2007 & Roos et al. & $\begin{array}{l}\text { Aplicação da } \\
\text { ferramenta fmea: } \\
\text { estudo de caso } \\
\text { em uma empresa } \\
\text { do setor de } \\
\text { transporte de } \\
\text { passageiros. }\end{array}$ & $\begin{array}{l}\text { Estudo de } \\
\text { caso }\end{array}$ & $\begin{array}{l}\text { Determinação de ações } \\
\text { que minimizem ou } \\
\text { eliminem modos de falha } \\
\text { em potencial em um dos } \\
\text { desdobramentos de } \\
\text { serviços prestados pela } \\
\text { empresa do setor de } \\
\text { transpor de passageiros. }\end{array}$ \\
\hline 2008 & Oliveira & $\begin{array}{l}\text { Marketing no pré- } \\
\text { desenvolvimento } \\
\text { de máquinas } \\
\text { agrícolas: um } \\
\text { modelo de } \\
\text { referência. }\end{array}$ & $\begin{array}{c}\text { pesquisas } \\
\text { bibliográfi-cas } \\
\text { e estudo de } \\
\text { multicasos }\end{array}$ & $\begin{array}{l}\text { Elaboração de um } \\
\text { modelo referencial de } \\
\text { marketing para a etapa } \\
\text { de pré-desenvolvimento } \\
\text { de máquinas agrícolas. }\end{array}$ \\
\hline 2010 & Carpinetti & $\begin{array}{l}\text { Gestão da } \\
\text { Qualidade: } \\
\text { Conceitos e } \\
\text { Técnicas. } \\
\end{array}$ & $\begin{array}{c}\text { Documen-tal; } \\
\text { documen- } \\
\text { tação indireta. }\end{array}$ & $\begin{array}{l}\text { Apresenta conceitos } \\
\text { sobre a gestão de } \\
\text { qualidade. }\end{array}$ \\
\hline 2010 & $\begin{array}{l}\text { Arabian - } \\
\text { Hoseynabad } \\
\text { y et al. }\end{array}$ & $\begin{array}{l}\text { Failure Modes } \\
\text { and Effects } \\
\text { Analysis (FMEA) } \\
\text { for wind turbines }\end{array}$ & $\begin{array}{l}\text { Estudo de } \\
\text { caso }\end{array}$ & $\begin{array}{c}\text { Comparação entre os } \\
\text { resultados quantitativos } \\
\text { de uma FMEA e dados de } \\
\text { campo de confiabilidade } \\
\text { de sistemas de turbinas } \\
\text { eólicas reais e seus } \\
\text { conjuntos. }\end{array}$ \\
\hline 2011 & Yang et al. & $\begin{array}{l}\text { Risk evaluation in } \\
\text { failure mode and } \\
\text { effects analysis of } \\
\text { aircraft turbine } \\
\text { rotor blades using } \\
\text { Dempster-Shafer } \\
\text { evidence theory } \\
\text { under uncertaitny }\end{array}$ & $\begin{array}{l}\text { Estudo de } \\
\text { caso }\end{array}$ & $\begin{array}{l}\text { Avaliação da prioridade } \\
\text { de risco dos modos de } \\
\text { falhas das pás do rotor de } \\
\text { uma turbina de uma } \\
\text { aeronave. }\end{array}$ \\
\hline 2012 & $\begin{array}{l}\text { Bonamoni et } \\
\text { al. }\end{array}$ & $\begin{array}{c}\text { Efeito da } \\
\text { Aplicação do } \\
\text { Fmea na } \\
\text { Priorização de } \\
\text { Riscos de Projetos } \\
\text { de } \\
\text { Desenvolvimento } \\
\text { de Software - } \\
\text { Produto }\end{array}$ & $\begin{array}{c}\text { Probabili-dade } \\
\text { versus } \\
\text { impactos }\end{array}$ & $\begin{array}{l}\text { Os resultados } \\
\text { apresentam mais acerto } \\
\text { para o uso do método } \\
\text { FMEA no gerenciamento } \\
\text { dos riscos em projetos de } \\
\text { software. }\end{array}$ \\
\hline 2012 & $\begin{array}{l}\text { Ahire and } \\
\text { Relkar }\end{array}$ & $\begin{array}{l}\text { Practical } \\
\text { Framework: }\end{array}$ & $\begin{array}{l}\text { Estudo de } \\
\text { caso }\end{array}$ & $\begin{array}{l}\text { Apresenta uma estrutura } \\
\text { prática para implementar }\end{array}$ \\
\hline
\end{tabular}




\begin{tabular}{|c|c|c|c|c|}
\hline & & $\begin{array}{l}\text { Implementing } \\
\text { OEE Method in } \\
\text { Manufacturing } \\
\text { Process } \\
\text { Environment }\end{array}$ & & $\begin{array}{l}\text { o OEE e um estudo de } \\
\text { caso foi discutido para } \\
\text { explicar detalhadamente } \\
\text { cada passo proposto. }\end{array}$ \\
\hline 2017 & Kang et al. & $\begin{array}{l}\text { Risk assessment } \\
\text { of floating } \\
\text { offshore wind } \\
\text { turbine based on } \\
\text { correlation-FMEA }\end{array}$ & $\begin{array}{l}\text { Estudo de } \\
\text { caso }\end{array}$ & $\begin{array}{l}\text { Obtenção de um } \\
\text { conjunto de falhas fracos } \\
\text { no projeto de turbinas } \\
\text { eólicas através de } \\
\text { coeficientes de } \\
\text { probabilidade. }\end{array}$ \\
\hline 2018 & Wang et al. & $\begin{array}{l}\text { A risk evaluation } \\
\text { and prioritization } \\
\text { method for FMEA } \\
\text { with prospect } \\
\text { theory and } \\
\text { Choquet integral }\end{array}$ & $\begin{array}{l}\text { Estudo de } \\
\text { caso }\end{array}$ & $\begin{array}{c}\text { Aplicação e validação de } \\
\text { um novo modelo de } \\
\text { FMEA. }\end{array}$ \\
\hline
\end{tabular}

Fonte: Próprio autor (2018).

\section{METODOLOGIA}

Lehfeld (1991) refere-se à pesquisa como sendo a inquisição, o procedimento sistemático e intensivo, que tem por objetivo descobrir e interpretar os fatos que estão inseridos em uma determinada realidade

A pesquisa científica pode ser classificada de quatro maneiras: quanto à abordagem, quanto à natureza, quanto aos objetivos e quanto aos procedimentos técnicos utilizados.

A Figura 4 demonstra classificações de pesquisa científica a partir dos autores Bertrand e Fransoo (2002), Gil (2007) e Silva e Menezes (2005).

Figura 4 - Classificações de pesquisa científica.

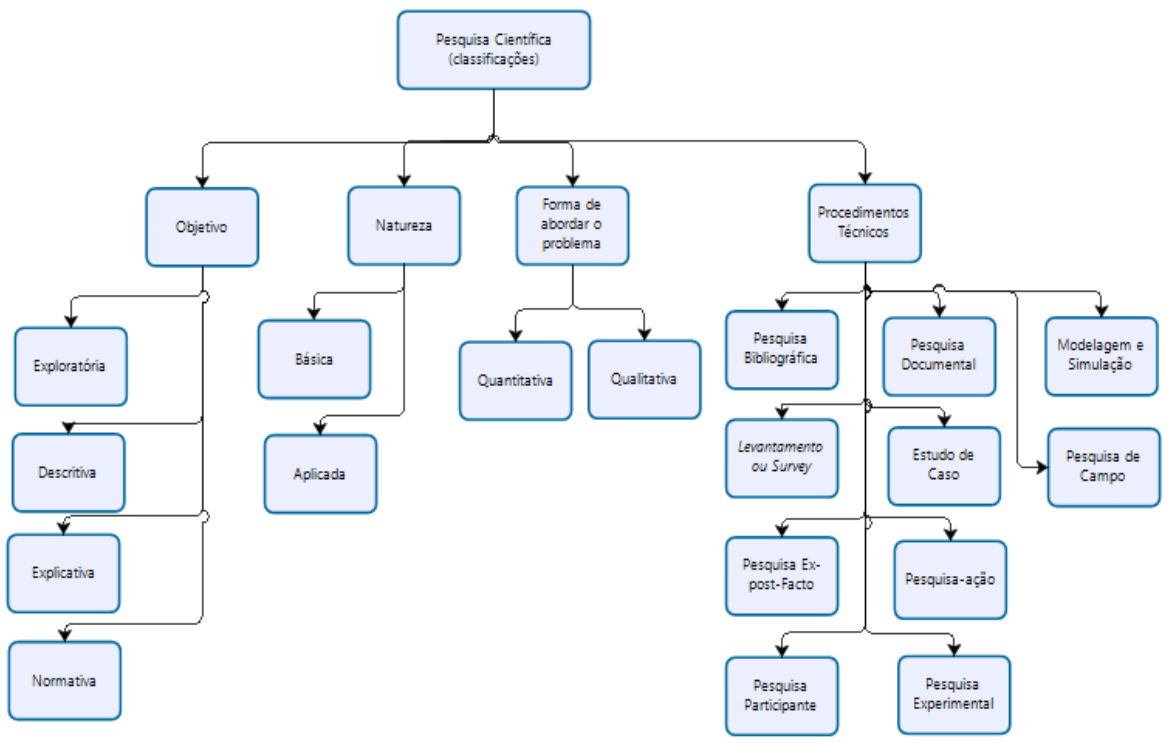

Fonte: Próprio autor. 


\section{CARACTERIZAÇÃO ETIPO DE PESQUISA}

Com base na Figura 4, o presente trabalho caracteriza-se por uma pesquisa com objetivo exploratório devido que, segundo Gil (2007), tem como objetivo principal o aperfeiçoamento ideias ou o descobrimento de intuições, proporcionando maior familiaridade com o problema, com objetivo de torna-lo mais explícito. A natureza da pesquisa é básica por ter o objetivo de gerar conhecimentos para aplicação prática, dirigido à solução de um problema específico. Em relação a abordagem do problema considera-se uma pesquisa de cunho qualitativo.

Os procedimentos metodológicos utilizados no presente trabalho são: pesquisa bibliográfica e focus group.

Utiliza-se a pesquisa bibliográfica (desk research) e a pesquisa documental como métodos de pesquisas integrados e complementares onde a partir delas analisa-se artigos científicos, livros, revistas, teses, sites e reportagens. A utilização desses meios tem o objetivo de obter conhecimento sobre assunto que está em estudo e também obter um princípio para dar sustentação à conclusão.

Já a utilização do focus group é devido a ser um tipo de entrevista de fácil aplicação e que se aproxima da realidade de cada pessoa. Segundo Oliveira et al. (1998), o foco ou o objetivo de análise é a interação dentro do grupo. Os participantes se influenciarem simultaneamente através das respostas, ideias e colocações durante a discussão, estimulados por comentários ou questões fornecidas pelo pesquisador ou outra pessoa.

\section{QUESTIONAMENTOS DE PESQUISA}

O questionamento de pesquisa se faz necessário para alcançar o propósito o qual é utilizar a ferramenta FMEA com o objetivo de analisá-la.

Os seguintes questionamentos de pesquisa são feitos:

Questão 1 (Q1): Como montar uma matriz FMEA para uma asa de revestimento metálico?

Questão 2 (Q2): Como identificar os possíveis itens que podem falhar em uma asa de revestimento metálico?

Questão 3 (Q3): Como determinar quais são os modos de falha mais relevantes no projeto de uma asa de avião?

Questão 4 (Q4): Como definir as possíveis melhorias para cada modo de falha?

\section{DELINEAMENTO DE PESQUISA}

O delineamento da pesquisa tem a função de fornecer um entendimento da forma na qual o trabalho se desdobra.

A Figura 5 apresenta o mapa mental do processo utilizado no presente trabalho que serve para esquematizar as etapas do projeto. Vale-se ressaltar que os questionamentos Q1, Q2, Q3 e Q4 são respondidos na seção 3.4 da 
metodologia, seção 4.1 da análise e resultados, seção 4.2 da análise e resultados e seção 4.3 da análise e resultados respectivamente.

Figura 5 - Mapa mental

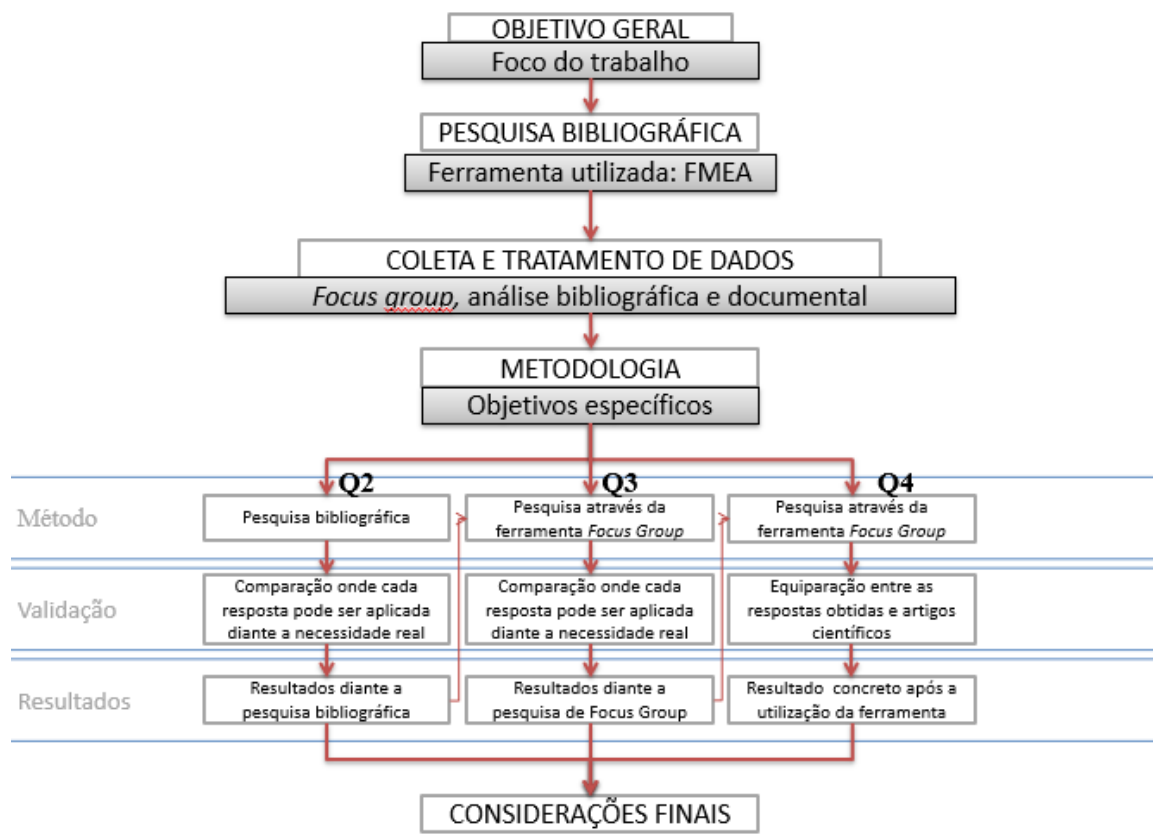

Fonte: Próprio autor.

\section{FORMA DE COLETA DE DADOS}

A forma de coleta de dados se deu a partir de pesquisas em livros e artigos, para assim poder desenvolver a seção de revisão bibliográfica do trabalho. Nessa seção, com a finalidade de explanar uma introdução sobre desenvolvimento de projetos, buscou-se obras as quais são referências nessa área para a disciplina de Projeto Integrado do curso de engenharia mecânica da Universidade Federal do Pampa - Campus Alegrete. Portanto, as obras escolhidas foram o livro dos autores Rozenfeld, Forcellini, Amaral, Toledo, Silva, Alliprandini e Scalice com o nome de "Gestão de desenvolvimento de produtos: uma referência para a melhoria do processo" e a obra de Alexandre Silva de Oliveira intitulada de "Marketing no Pré-Desenvolvimento de Máquinas Agrícolas: Um Modelo de Referência" a qual foi pesquisada no dia 13/11/2018 e estava disponível através do link <http://www.dralexandreoliveira.com.br/Artigosteses.htm>.

Já com intuito de esclarecer a ferramenta FMEA, utilizaram-se artigos os quais foram pesquisados através da ferramenta de pesquisa de artigos Science Direct, onde a palavra-chave pesquisada foi: "FMEA". Os resultados selecionados foram os artigos de livre acesso, presentes nas três primeiras páginas, que abordam o assunto em que se utilizou a ferramenta para o desenvolvimento de um produto ou de um processo. Destaca-se que essa pesquisa foi realizada na sala 104 da Universidade Federal do Pampa - Campus Alegrete na data de $13 / 11 / 2018$.

Para a seleção dos possíveis componentes que podem falhar, realizaram-se pesquisas em bibliografias disponíveis, a fim de encontrar os possíveis equipamentos que causam falha de uma asa de revestimento metálico. Os modos 
de falha foram obtidos através de livros, os quais foram pesquisados por meio do software de pesquisa do Google na data 14/11/2018. Para a seleção dos artigos, o assunto pesquisado foi: "conhecimentos técnicos de aeronaves asa" onde a partir dos resultados de pesquisa selecionou-se o sétimo link apresentado do site do slideshare.

Já para obter-se as respostas para fazer o ranqueamento de cada modo de falha, com o objetivo de calcular qual o seu grau de prioridade através do NPR, optou-se pela realização de um focus group entre os dois alunos integrantes do grupo. Esta etapa foi realizada no dia 16/11/2018 na sala 104, atual sala de estudos da Universidade Federal do Pampa campus Alegrete, onde os assuntos foram: "Quais os modos de falhas possíveis para cada item? Qual o ranqueamento que cada modo de falha em relação aos índices de severidade, ocorrência e deteç̧ão?".

Para obtenção das ações de melhoria também se utilizou o método de focus group entre os dois alunos integrantes do grupo na mesma data e local, porém com os assuntos centrais diferentes. Os assuntos abordados foram: "Quais são as possíveis melhorias que visam diminuir os riscos encontrados em cada item? Qual seria o novo ranqueamento após a implantação dessas melhorias?".

\section{FORMA DE TRATAMENTO DOS DADOS}

A forma de tratamento de dados utilizado se deu a partir da utilização do software Microsoft Office Excel onde foi possível realizar a montagem da matriz FMEA através da compreensão de livros, artigos e teses conforme mostrados na seção 2.2 .

\section{VALIDAÇÃO DOS DADOS}

Para a validação dos dados coletados, através de uma comparação entre o resultado do objetivo geral do artigo, em relação ao encontrado na bibliografia com o intuito de obter informações fieis, evitando prejudicar o resultado da pesquisa.

A coleta de referências bibliográficas utilizadas para a validação dos resultados foi através da ferramenta de pesquisa de artigos Science Direct, onde as palavras chaves pesquisadas foram: "stringers, importants, wing". O resultado selecionado foi o vigésimo primeiro o qual é um artigo científico recente que aborda o assunto sobre os processos de fabricação de aeronaves com enfoque nas asas.

\section{RESULTADOS E DISCUSSÕES}

Para obter a matriz FMEA pronta utilizou-se o método de pesquisa bibliográfica, juntamente com a ferramenta de focus group para obtenção de dados os mais coerentes possíveis.

Portanto, o primeiro passo para se realizar a construção da matriz é identificar os possíveis itens que possam falhar. 


\section{OBTENCCÃO DOS POSSÍVEIS ITENS QUE PODE OCORRER FALHAS}

A obtenção dos componentes se deu a partir da utilização da pesquisa bibliográfica. Nesta etapa procurou-se encontrar os itens presentes numa asa de revestimento metálico de uma aeronave. Para isso necessitou-se consultar a obra de Homa em sua 270 edição a qual foi comentada na seção 2.3 , sendo possível encontrar os componentes que são possíveis causadores de falha de uma asa.

O Quadro 4 apresenta os componentes de uma asa de revestimento metálico segundo Homa (2007).

Quadro 4-Componentes que podem ocorrer falha.

\begin{tabular}{|c|}
\hline Descrição \\
\hline Acoplamento fuselagem \\
\hline Longarinas \\
\hline Nervuras \\
\hline Braço de comando \\
\hline Articulações \\
\hline Aileron \\
\hline Flaps \\
\hline Slats \\
\hline Eixos flexíveis \\
\hline Servos motores \\
\hline Freios aerodinâmicos \\
\hline Revestimento \\
\hline
\end{tabular}

Fonte: Próprio autor (2018).

Vale-se ressaltar que os componentes presentes na Tabela 4 são utilizados para uma asa fixa, com revestimento metálico de uma aeronave.

\section{RELEVÂNCIA DOS MODOS DE FALHA}

Para fazer a relevância dos modos de falhas necessita-se, primeiramente, encontrar os possíveis modos de falha para cada item, logo após ranqueá-los através do seu grau de severidade, grau de ocorrência e o grau de detecção. A partir do ranqueamento de cada modo de falha é possível então encontrar a relevância dos mesmos. A obtenção dos modos de falhas foi determinada através da utilização do método de focus group, o qual também serviu para fazer o ranqueamento de cada modo com a finalidade de poder calcular a relevância dos mesmos.

A relevância de cada modo de falha é apresentada no Quadro 5.

Quadro 5 - Relevância dos modos de falha.

\begin{tabular}{|c|c|c|c|c|c|c|c|c|c|}
\hline Descrição & Função & $\begin{array}{c}\text { Tipo de } \\
\text { falha }\end{array}$ & $\begin{array}{c}\text { Efeito da } \\
\text { falha }\end{array}$ & $\begin{array}{c}\text { Causa da } \\
\text { falha }\end{array}$ & $\begin{array}{c}\text { Controles } \\
\text { Atuais }\end{array}$ & S & O & D & NPR \\
\hline $\begin{array}{c}\text { Acoplamento } \\
\text { asa/fuselagem }\end{array}$ & $\begin{array}{c}\text { Fixar da asa } \\
\text { na estrutura }\end{array}$ & Quebra & $\begin{array}{c}\text { Carga } \\
\text { excessiva, } \\
\text { defeitos na } \\
\text { fabricação, } \\
\text { aeronal }\end{array}$ & $\begin{array}{c}\text { Visual e } \\
\text { teste } \\
\text { acoplamento }\end{array}$ & 9 & 6 & 1 & 54 \\
\hline Longarinas & $\begin{array}{c}\text { Resistir } \\
\text { esforços }\end{array}$ & Quebra & $\begin{array}{c}\text { Queda da } \\
\text { aeronave }\end{array}$ & $\begin{array}{c}\text { Carga } \\
\text { excessiva, }\end{array}$ & $\begin{array}{c}\text { Visual e } \\
\text { teste }\end{array}$ & 9 & 2 & 5 & 90 \\
\hline
\end{tabular}




\begin{tabular}{|c|c|c|c|c|c|c|c|c|c|}
\hline & durante voo & & & $\begin{array}{c}\text { fadiga, } \\
\text { defeito na } \\
\text { fabricação }\end{array}$ & & & & & \\
\hline Nervuras & $\begin{array}{c}\text { Transmitir } \\
\text { esforços do } \\
\text { revestimento } \\
\text { para } \\
\text { longarina }\end{array}$ & Quebra & $\begin{array}{l}\text { Perda de } \\
\text { rendimen- } \\
\text { to de voo }\end{array}$ & $\begin{array}{l}\text { Impacto, } \\
\text { fadiga }\end{array}$ & Visual & 9 & 2 & 4 & 72 \\
\hline $\begin{array}{l}\text { Braço de } \\
\text { comando }\end{array}$ & $\begin{array}{c}\text { Transmitir } \\
\text { movimento } \\
\text { o aileron }\end{array}$ & Quebra & $\begin{array}{l}\text { Trava- } \\
\text { mento do } \\
\text { aileron }\end{array}$ & $\begin{array}{c}\text { Fadiga, } \\
\text { defeito na } \\
\text { fabricação }\end{array}$ & $\begin{array}{c}\text { Teste } \\
\text { mecânico }\end{array}$ & 8 & 4 & 1 & 32 \\
\hline Articulações & $\begin{array}{c}\text { Transmitir } \\
\text { movimento } \\
\text { ao aileron e } \\
\text { spoilers }\end{array}$ & Quebra & $\begin{array}{l}\text { Trava- } \\
\text { mento do } \\
\text { aileron }\end{array}$ & $\begin{array}{c}\text { Fadiga, } \\
\text { defeito na } \\
\text { fabricação }\end{array}$ & $\begin{array}{c}\text { Teste } \\
\text { mecânico }\end{array}$ & 8 & 4 & 1 & 32 \\
\hline Aileron & $\begin{array}{c}\text { Imprimir } \\
\text { movimento } \\
\text { de } \\
\text { rolamento a } \\
\text { aeronave }\end{array}$ & Quebra & $\begin{array}{l}\text { Queda da } \\
\text { aeronave }\end{array}$ & $\begin{array}{c}\text { Impacto, } \\
\text { fadiga, carga } \\
\text { excessiva }\end{array}$ & Visual & 9 & 3 & 1 & 27 \\
\hline Flaps & $\begin{array}{c}\text { Produzir } \\
\text { sustentação } \\
\text { na } \\
\text { aterrissagem } \\
\text { e decolagem }\end{array}$ & Quebra & $\begin{array}{l}\text { Queda da } \\
\text { aeronave }\end{array}$ & $\begin{array}{l}\text { Impacto, } \\
\text { carga } \\
\text { excessiva }\end{array}$ & Visual & 9 & 3 & 1 & 27 \\
\hline Slats & $\begin{array}{c}\text { Produzir } \\
\text { sustentação } \\
\text { na } \\
\text { aterrissagem } \\
\text { e decolagem }\end{array}$ & Quebra & $\begin{array}{l}\text { Queda da } \\
\text { aeronave }\end{array}$ & $\begin{array}{l}\text { Impacto, } \\
\text { carga } \\
\text { excessiva }\end{array}$ & Visual & 9 & 4 & 1 & 36 \\
\hline Eixos flexíveis & $\begin{array}{c}\text { Alimentar } \\
\text { sistemas de } \\
\text { atuadores } \\
\text { dos } \\
\text { elementos } \\
\text { de controle } \\
\text { (flaps e slats) }\end{array}$ & $\begin{array}{l}\text { Rompi- } \\
\text { mento }\end{array}$ & $\begin{array}{l}\text { Trava- } \\
\text { mento } \\
\text { dos flaps } \\
\text { e slats }\end{array}$ & Fadiga & $\begin{array}{c}\text { Teste } \\
\text { mecânico }\end{array}$ & 8 & 3 & 1 & 24 \\
\hline Servos motores & $\begin{array}{c}\text { Transmitir } \\
\text { movimento }\end{array}$ & Queimar & $\begin{array}{l}\text { Queda da } \\
\text { aeronave }\end{array}$ & $\begin{array}{l}\text { Defeito de } \\
\text { fabricação }\end{array}$ & Teste & 8 & 3 & 1 & 24 \\
\hline $\begin{array}{c}\text { Freios } \\
\text { aerodinâmicos }\end{array}$ & $\begin{array}{l}\text { Impedir } \\
\text { aumento de } \\
\text { velocidade } \\
\text { excessiva }\end{array}$ & Quebra & $\begin{array}{l}\text { Queda da } \\
\text { aeronave }\end{array}$ & $\begin{array}{l}\text { Impacto, } \\
\text { carga } \\
\text { excessiva }\end{array}$ & $\begin{array}{c}\text { Teste } \\
\text { mecânico }\end{array}$ & 9 & 3 & 1 & 27 \\
\hline Revestimento & Estrutural & $\begin{array}{l}\text { Rompi- } \\
\text { mento }\end{array}$ & $\begin{array}{l}\text { Queda da } \\
\text { aeronave }\end{array}$ & $\begin{array}{l}\text { Impacto, } \\
\text { fadiga }\end{array}$ & Visual & 9 & 3 & 1 & 27 \\
\hline
\end{tabular}

Fonte: Próprio autor (2018).

Vale-se destacar atenção para os três primeiros itens que tiveram maior relevância os quais foram as longarinas, nervuras e acoplamento entre a asa e a fuselagem.

As longarinas são componentes estruturais internos da asa tendo a função de resistir esforços durante o voo. Possui grande relevância e deve merecer cuidado, uma vez que se esse componente quebrar devido a fortes impactos, pode ocasionar na queda da aeronave. 
Já as nervuras, as quais também são componentes estruturais da asa, tem a função de transmitir os esforços dos revestimentos para longarinas, além de serem elas que dão o formato dinâmico da asa, possuem grande relevância pelo fato de que caso ocorra sua quebra, também devido a fortes impactos, é de difícil deteç̧ão e pode ocasionar perdas de rendimento durante o voo.

O acoplamento asa/fuselagem possui grande relevância devido fixar a asa na estrutura da aeronave, caso haja a quebra dela, ocasiona na queda da aeronave ou a perda de controle podendo vir a colisão.

Esses itens, conforme são de maiores relevâncias, devem receber ações que previnam e diminuam a probabilidade de suas falhas.

\section{AÇÕES DE MELHORIA}

Após a obtenção da relevância dos modos de falhas faz-se a correlação dos mesmos verificando quais itens devem receber maior atenção. Identificado os itens através do NPR, faz-se então um plano de melhoria para cada um deles com a finalidade de atenuar os riscos de falhas. É de suma importância obter essas melhorias na fase de projeto detalhado uma vez que elimina obtenção de problemas futuros.

O Quadro 6 apresenta as ações de melhoria de cada item respectivamente. Nota-se que há uma diminuição nos índices de severidade, ocorrência e detecção em decorrência as ações que devem ser implantadas para cada item.

Ressalta-se além das ações recomendadas no quadro, também se pode colocar outras ações que previnam falhas após de finalizado o projeto. Uma das ideias é a adesão de um check list que deve ser feito antes de cada voo, identificando possíveis erros e, assim, fazer uma manutenção corretiva nas falhas encontradas.

Quadro 6 - Ações de melhoria.

\begin{tabular}{|c|c|c|c|c|c|c|}
\hline \multirow{2}{*}{ Descrição } & \multicolumn{2}{|c|}{ Ações de melhoria } & \multicolumn{4}{|c|}{$\begin{array}{c}\text { Índices } \\
\text { atualizados }\end{array}$} \\
\hline & $\begin{array}{c}\text { Ações } \\
\text { recomendadas }\end{array}$ & $\begin{array}{c}\text { Ações } \\
\text { implantadas }\end{array}$ & $S$ & 0 & D & NPR \\
\hline $\begin{array}{l}\text { Acoplamento } \\
\text { fuselagem }\end{array}$ & $\begin{array}{c}\text { Reforçar } \\
\text { acoplamento }\end{array}$ & $\begin{array}{c}\text { Não sofrer altos } \\
\text { impactos e testar } \\
\text { qualidade }\end{array}$ & 9 & 2 & 1 & 18 \\
\hline Longarinas & $\begin{array}{l}\text { Implementar } \\
\text { material com maior } \\
\text { resistência mecânica }\end{array}$ & $\begin{array}{c}\text { Uso de material } \\
\text { com boa } \\
\text { resistência } \\
\text { mecânica }\end{array}$ & 9 & 3 & 1 & 27 \\
\hline Nervuras & $\begin{array}{c}\text { Aumentar espessura } \\
\text { da nervura }\end{array}$ & $\begin{array}{c}\text { Nervura com } \\
\text { maior espessura }\end{array}$ & 9 & 1 & 2 & 18 \\
\hline Braço de comando & Verificar qualidade & $\begin{array}{c}\text { Teste de } \\
\text { qualidade e de } \\
\text { capacidade parar } \\
\text { suportar } \\
\text { esforços }\end{array}$ & 8 & 2 & 1 & 16 \\
\hline Articulações & Verificar qualidade & $\begin{array}{c}\text { Teste de } \\
\text { qualidade e de } \\
\text { capacidade parar }\end{array}$ & 8 & 2 & 1 & 16 \\
\hline
\end{tabular}




\begin{tabular}{|c|c|c|c|c|c|c|}
\hline & & $\begin{array}{l}\text { suportar } \\
\text { esforços }\end{array}$ & & & & \\
\hline Aileron & $\begin{array}{l}\text { Alertar sobre } \\
\text { fragilidade do } \\
\text { componente }\end{array}$ & $\begin{array}{c}\text { Controle de } \\
\text { fortes impactos }\end{array}$ & 9 & 2 & 1 & 18 \\
\hline Flaps & $\begin{array}{l}\text { Alertar sobre } \\
\text { fragilidade do } \\
\text { componente }\end{array}$ & $\begin{array}{c}\text { Controle de } \\
\text { fortes impactos }\end{array}$ & 9 & 2 & 1 & 18 \\
\hline Slats & $\begin{array}{l}\text { Alertar sobre } \\
\text { fragilidade do } \\
\text { componente }\end{array}$ & $\begin{array}{c}\text { Controle de } \\
\text { fortes impactos }\end{array}$ & 9 & 2 & 1 & 18 \\
\hline Eixos flexíveis & Verificar qualidade & $\begin{array}{c}\text { Teste de } \\
\text { qualidade e de } \\
\text { capacidade parar } \\
\text { suportar } \\
\text { esforços }\end{array}$ & 8 & 2 & 1 & 16 \\
\hline Servos motores & Verificar qualidade & $\begin{array}{c}\text { Teste de } \\
\text { qualidade e de } \\
\text { capacidade parar } \\
\text { suportar } \\
\text { esforços }\end{array}$ & 8 & 2 & 1 & 16 \\
\hline Freios aerodinâmicos & $\begin{array}{l}\text { Alertar sobre } \\
\text { fragilidade do } \\
\text { componente }\end{array}$ & $\begin{array}{c}\text { Controle de } \\
\text { fortes impactos }\end{array}$ & 9 & 2 & 1 & 18 \\
\hline Revestimento & Verificar material & $\begin{array}{l}\text { Uso de material } \\
\text { com boa } \\
\text { resistência } \\
\text { mecânica e não } \\
\text { sofrer fortes } \\
\text { impactos }\end{array}$ & 9 & 2 & 1 & 18 \\
\hline
\end{tabular}

Fonte: Próprio autor (2018).

\section{VALIDAÇÃO}

Essa seção tem a finalidade de reconhecer e validar os resultados obtidos no trabalho através da análise de artigo científico.

Ao consultar o trabalho de Diaz et al. (2017) comprova-se que os materiais que recebem estresse, são os principais componentes os quais devem receber uma maior atenção. Os materiais citados pelo autor são nervuras, longarinas e o revestimento.

No presente trabalho, nota-se que ao calcular a relevância dos modos de falhas, os principais itens apresentados são longarinas, nervuras e o acoplamento asa/fuselagem. Portanto, tem-se os dois primeiros itens coerentes com o autor, já o acoplamento asa/fuselagem há uma discrepância podendo ser causada devido o autor não considerar em sua obra o acoplamento entre a asa e a fuselagem.

\section{CONSIDERAÇÕES FINAIS}

O método FMEA visa detectar possíveis falhas que podem o ocorrer em determinado processo ou produto. $\mathrm{O}$ objetivo desse trabalho tem a finalidade de tentar tornar público os riscos que são considerados no projeto de uma asa de revestimento metálico de uma aeronave. Com a finalização do trabalho, pode-se dizer que a matriz contribui para a melhoraria e otimização do produto ao se 
fazer uso da mesma na fase de projeto detalhado. A vantagem do uso da ferramenta, conforme já foi dito, é explicitar as falhas potenciais, causas e meios evitando-as. Então, deve-se dar maior atenção para itens que apresentam maior relevância, evidenciados através do NPR, por meio de ações de melhoria.

Tendo em vista as hipóteses $\mathrm{H} 2, \mathrm{H} 3$ e H4, ressalta-se que elas atendem os seus respectivos objetivos alcançando os resultados esperados. Em relação ao objetivo geral que é comprovar as respostas obtidas pela matriz FMEA para uma asa de revestimento metálico de uma aeronave, a hipótese de possível solução H1, que é validação dos resultados obtidos atende de forma esperada o objetivo, uma vez que é possível comprovar os resultados através da validação entre outro trabalho.

Como crítica ao presente trabalho, a utilização do método convencional do FMEA via RPN ser uma maneira simples e útil na prática, ainda possui muitos inconvenientes. Roos et al. (2018) cita alguns como: (i) Na FMEA convencional, a abordagem RPN usa números nítidos para determinar as pontuações dos três fatores de risco, O, S e D, no entanto, é impossível avaliar os modos de falha por valores numéricos exatos em muitos cenários do mundo real. (ii) Os três fatores de risco no método RPN devem ter o mesmo peso de importância, enquanto que em aplicações reais a importância de cada fator de risco pode ser desigual. (iii) A combinação diferente de classificações de fatores de risco pode gerar o mesmo valor de RPN, o que não é efetivo no gerenciamento prático de riscos. (iv) 0 método adotado para calcular o RPN é a falta de evidência científica. (v) As relações de interação entre fatores de risco não são consideradas no FMEA convencional. Consequentemente, há uma necessidade de melhorar ainda mais o método FMEA convencional, que pode se tornar uma ferramenta mais flexível para o gerenciamento de risco e segurança do sistema.

Como sugestão de trabalhos futuros indica-se realizar um novo trabalho no qual utilize métodos para agregação de valor prospecto dos modos de falha em cada item de risco. Como exemplo de ferramentas tem-se fuzzy measure e Coquet integral. 


\title{
Application of the FMEA tool for the construction of a metallic coating wing
}

\begin{abstract}
Failure Mode and Effect Analyzes (FMEA) is considered one of the most effective risk analysis methods which has been widely adopted in several fields for system security and reliability improvements. The present study aims to assemble an FMEA matrix of a metal coating wing. The methodologies used in the study consist of bibliographic analysis and the Focus Group to determine the severity, occurrence and detection indices, thus, to calculate the NPR and find the relevance of each mode of failure. For the actions of improvements of each failure mode, the Focus Group technique was also used to find these actions. As results of this study, we have as fault modes of greater relevance the spars, ribs and coupling between the wing and the fuselage.
\end{abstract}

KEYWORDS: FMEA. Failure modes. Improvement actions. Risk analysis. 


\section{REFERÊNCIAS}

AHIRE, C.P., RELKAR, A.S. Correlating Failure Mode Effect Analysis (FMEA) \& Over all Equipment Effectiveness (OEE), 2012. crossref

ARABIAN-HOSEYNABADI, H., ORAEE, H., TAVNER, P.J., 2010. Failure modes and effects analysis (FMEA) for wind turbines. Electr. Power Energy Syst. 32, 817-824. 2010. crossref

BASTOS, A. L. A. FMEA (Failure Mode and Effect Analysis) Como Ferramenta de Prevenção da Qualidade em Produtos e Processos - Uma Avaliação da Aplicação em um Processo Produtivo de Usinagem de Engrenagem. ENEGEP - Fortaleza, CE, Brasil, 2006.

CARPINETTI, L. C. R. Gestão da Qualidade: Conceitos e Técnicas. São Paulo: Editora Atlas, 2010.

DIAZ, C.; JIN, Y.; ARES, E. Cycle time study of wing spar assembly on aircraft factory. Procedia Manufacturing, vol. 13, p. 1019-1025, 2017. crossref

GIL, A. C. Como Elaborar Projetos de Pesquisa. 4. ed. São Paulo. Editora Atlas, 2007.

HOMA, J. M. Aeronaves e Motores (Conhecimentos Técnicos). 27. ed. Editora Asa, 194 p. 2007.

KANG, J.; SUN, L.; SUN, H.; WU, C. Risk assessment of floating offshore wind turbine based on correlation-FMEA. Ocean Engineering 129, 382-388, 2017.

\section{crossref}

LIU, H. C. FMEA Using Uncertainty Theories and MCDM Methods. 2016, Springer, Singapore, 2016. crossref

OLIVEIRA, A; DALLMEYER, A. U.; ROMANO, L. N.; BISOGNIN, A. Marketing no Prédesenvolvimento de Máquinas Agrícolas: Um Modelo de Referência, In: IX Congreso Latinoamericano y del Caribe de Ingeniería Agrícola e CLIA 2010 XXXIX Congresso Brasileiro de Engenharia Agrícola - CONBEA; 2010, Vitória - ES, Brasil, 4 p., 2010.

PALADY, P. FMEA: Análise dos Modos de Falha e Efeitos: prevendo e prevenindo problemas antes que ocorram. 3. ed. São Paulo: IMAM, 2004. 
PUENTE, J.; et al. Um sistema de apoio à decisão para aplicação do FMEA International Journal of Quality \& Reliability Management, n. 2, v. 19, 2002

ROOS, C.; DIESEL, L.; MORAES, J. A. R.; ROSA, L. C. APLICAÇÃO DA FERRAMENTA FMEA: ESTUDO DE CASO EM UMA EMPRESA DO SETOR DE TRANSPORTE DE PASSAGEIROS. TECNO-LÓGICA, Santa Cruz do Sul, v. 11, n. 1 e 2, p. 29-32, jan./jun. 2007

ROZENFELD, H.; FORCELLINI, F. A.; AMARAL, D. C.; TOLEDO, J. C.; SILVA, S. L.; ALLIPRANDINI, D. H.; SCALICE, R. K. Gestão de desenvolvimento de produtos: uma referência para a melhoria do processo. São Paulo: Saraiva, 2006. 542 p.

WANG, W.; LIU, X.; QIN, Y.; FU, Y. A risk evaluation prioritization method for FMEA with prospect theory and Choquet integral. Safety Science 110, 152-163, 2018.

YANG, J.; HUANG H. Z.; HE, L. P.; ZHU S. P.; WEN D. Risk evaluation in failure mode and effects analysis of aircraft turbine rotor blades using Dempster-Shafer evidence theory under uncertainty. Engineering Failure Analysis 18, 2084-2092, 2011. crossref

ZHOU, Q.; THAI, V. V., 2016. Fuzzy and grey theoris in failure mode and effect analysis for tanker equipment failure prediction. Safety Science. 83, 74-79, 2016. crossref

ZORZO, R.; OLIVEIRA, A. S. de. Hipóteses sobre as propriedades geométricas primárias da asa de um carro voador. Revista Ciência e Tecnologia, v. 8, n. 33, p.10, 2015.
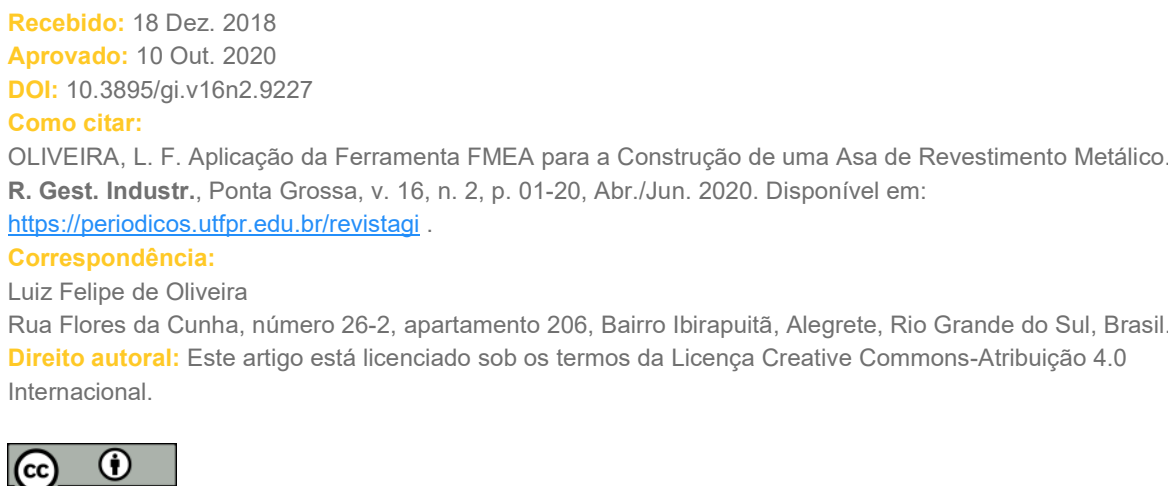